\title{
Enhanced susceptibility to tumor necrosis factor-related apoptosis-inducing ligand-mediated apoptosis in oral squamous cell carcinoma cells treated with phosphatidylinositol 3-kinase inhibitors
}

\author{
MAKIKO UCHIDA, MASAYASU IWASE, SAYAKA TAKAOKA, SAYAKA YOSHIBA, GEN KONDO, \\ HITOSHI WATANABE, MASARU OHASHI, MASAO NAGUMO and SATORU SHINTANI \\ Department of Oral and Maxillofacial Surgery, Showa University School of Dentistry, \\ 2-1-1 Kitasenzoku, Ota-ku, Tokyo 145-8515, Japan
}

Received January 22, 2007; Accepted March 2, 2007

\begin{abstract}
In general, oral squamous cell carcinoma (OSCC) cells are relatively resistant to tumor necrosis factor-related apoptosis-inducing ligand (TRAIL)-mediated apoptosis during culture in vitro. Here, we studied the role of phosphatidylinositol 3-kinase (PI 3-K)/Akt in survival and apoptosis of these cells. The PI 3-K inhibitors wortmannin and LY294002 markedly suppressed phosphorylation of Akt and accelerated TRAIL-mediated apoptosis in OSCC cells. Addition of TRAIL to PI 3-K inhibitor-treated cells resulted in caspase-8 activation and loss of mitochondrial membrane potential. Furthermore, inhibitors of caspase- $3,-8$ and -9 reduced the accelerative effect of PI 3-K inhibitors on TRAIL-mediated apoptosis. These results suggest that the pro-apoptotic effect of PI 3-K inhibitors on TRAIL-mediated apoptosis may contribute to both the extrinsic and intrinsic pathways. Although PI 3-K inhibitors did not affect expression of the TRAIL receptors DR4 and DR5, we observed a marked reduction in expression of cellular FLICE-inhibitory protein (c-FLIP), Bcl-2, cellular inhibitor of apoptosis protein-1 (cIAP-1) and X-linked IAP (XIAP), whereas Bax was up-regulated and no significant difference was observed in expression of Bcl-xL, Bak or cIAP-2. Therefore, the PI 3-K/Akt signaling pathway provides partial regulation of TRAIL-mediated apoptosis in OSCC cells via modulation of c-FLIP, Bcl-2, Bax, cIAP-1 and XIAP expression. These results suggest that PI 3-K inhibitors may represent a novel strategy for overcoming resistance to TRAILmediated apoptosis in OSCC cells.
\end{abstract}

Correspondence to: Dr Masayasu Iwase, Department of Oral and Maxillofacial Surgery, Showa University School of Dentistry, 2-1-1 Kitasenzoku, Ota-ku, Tokyo 145-8515, Japan

E-mail: iwase@senzoku.showa-u.ac.jp

Key words: apoptosis, cellular FLICE-inhibitory protein, phosphatidylinositol 3-kinase/Akt, squamous cell carcinoma, tumor necrosis factor-related apoptosis-inducing ligand

\section{Introduction}

Tumor necrosis factor (TNF)-related apoptosis-inducing ligand (TRAIL) is a member of the TNF superfamily that was identified originally through sequence homology to Fas ligand (FasL) and TNF $(1,2)$. TRAIL can induce apoptosis in a variety of tumor cells by engaging the death receptors DR4 and DR5, resulting in activation of the extrinsic apoptotic pathway $(3,4)$. In the extrinsic pathway, receptor-mediated activation of caspase- 8 and -10 is followed by activation of caspase-3, which cleaves intracellular substrates leading to cell death. The intrinsic or mitochondrial pathway is linked to the extrinsic pathway through activated caspase- 8 , which cleaves the pro-apoptotic Bcl-2 family member Bid, producing a truncated fragment that associates with Bax. The Bid/Bax complex induces mitochondrial release of cytochrome $\mathrm{c}$, formation of the apoptosome and activation of caspase-9, followed by activation of executioner caspase-3, -6 and -7, which in turn promote further cleavage of intracellular proteins and cell death (5).

Many tumor cells, including the majority of squamous cell carcinoma (SCC) cells, also express DR4 and DR5 on their surfaces (6). TRAIL receptors are expressed in a variety of cancer and transformed cells, as well as in normal cells, where they have little effect (7). However, the response to TRAIL can be highly variable and resistance is observed in many types of cancer $(5,8)$. The initiation of apoptosis is controlled by integration of both pro- and anti-apoptotic signal transduction pathways, which mediate stimulation including the signaling via death receptors (9). Although the TRAIL death pathway is well defined, no dominant mechanism has yet been identified for resistance to TRAIL-induced cell death. Several intracellular anti-apoptotic molecules, such as members of the anti-apoptotic Bcl-2 and inhibitor of apoptosis protein (IAP) families, as well as cellular FLICE-inhibitory protein (c-FLIP), have been shown to inhibit the apoptotic signaling cascade via inhibition of mitochondrial cytochrome $\mathrm{c}$ release, apoptosome formation and recruitment of procaspase- 8 to the death receptor domain (10-13). In addition, death receptor mutations and deficiencies in caspase- 8 and Bax have been implicated in TRAIL resistance (4,13-17). 
Although intracellular mediators of apoptosis are currently being investigated, they remain largely unknown. Phosphatidylinositol 3-kinase (PI 3-K) is known to control cell survival/ death through phosphorylation of Akt in cancer cells (18-20). Activated Akt has been shown to play a role in growth factor- and cytokine-mediated survival, and it protects cells from apoptosis induced by a variety of stimuli (21). The PI 3-K/Akt signaling pathway also controls death receptor-mediated apoptosis in various cells, including cancer cells (22-24). However, the mechanism by which TRAILmediated apoptosis is attenuated via the PI 3-K/Akt signaling pathway remains unclear. Activated Akt phosphorylates Bad, procaspase-9, forkhead, cyclic AMP response element-binding protein and IкB kinase, resulting in suppression of the apoptotic signaling cascade and expression of anti-apoptotic genes (18-20). Furthermore, Akt has been shown to mediate downregulation of the pro-apoptotic Bcl-2 family and up-regulation of the anti-apoptotic c-FLIP, IAPs and Bcl-2 family proteins (25-27).

Strategies to overcome these resistance mechanisms are under intensive investigation. In this study, we examined whether or not PI 3-K inhibitors can affect the susceptibility of oral SCC (OSCC) cells to TRAIL-mediated apoptosis. In addition, we considered their effect on the expression of c-FLIP, as well as Bcl-2 and IAP family proteins. We demonstrated that in OSCC cells PI 3-K inhibitors enhance TRAILmediated apoptosis through modulation of c-FLIP, Bcl-2, Bax, cellular IAP (cIAP)-1 and X-linked IAP (XIAP).

\section{Materials and methods}

Reagents. DMEM and FBS were obtained from Gibco-BRL (Gaithersburg, MD). Recombinant human soluble TRAIL, antiDR4, anti-DR5, and the MEBCYTO apoptosis kit (employing FITC-conjugated annexin V) were purchased from MBL (Nagoya, Japan). Mouse anti-FLIP monoclonal antibody (mAb) was obtained from Alexis Corp. (Lausanne, Switzerland). We used mAbs against the following: Bax, cIAP-1, cIAP-2, XIAP and active caspase-8 (R\&D Systems Inc., Minneapolis, $\mathrm{MN}$ ); Bak (Stressgen Biotechnology, Victoria, Canada); and Bcl-2, Bcl-xL, Akt and phospho-Akt (Ser 473) (Santa Cruz Biotechnology, Santa Cruz, CA). Control antibodies were obtained from Pharmingen (San Diego, CA). We used caspase inhibitors against the following: caspase family (VAD-FMK); caspase-3 (DEVD-FMK); caspase-8 (IETD-FMK); caspase-9 (LEHD-FMK); and FMK negative control (FA-FMK; Trevigen Inc., Gaithersburg, MD). The PI 3-K inhibitors wortmannin and LY 294002 were obtained from Calbiochem (San Diego, CA) and Cayman Chemical (Ann Arbor, MI), respectively. All other chemicals were of analytical grade.

Cell lines and culture conditions. The human OSCC lines HSC-2 and NA were grown as adherent monolayers. HSC-2 and NA are cell lines established from SCC of the oral cavity. Cells were maintained in DMEM supplemented with $10 \%$ heat-inactivated FBS, 2 mM L-glutamine and antibiotics (100 U/ml penicillin and $100 \mu \mathrm{g} / \mathrm{ml}$ streptomycin) at $37^{\circ} \mathrm{C}$ in a humidified atmosphere of $5 \% \mathrm{CO}_{2}$. Neither wortmannin $(500 \mathrm{nM})$ nor LY294002 $(30 \mu \mathrm{M})$ had any effect on cell viability under the conditions indicated.

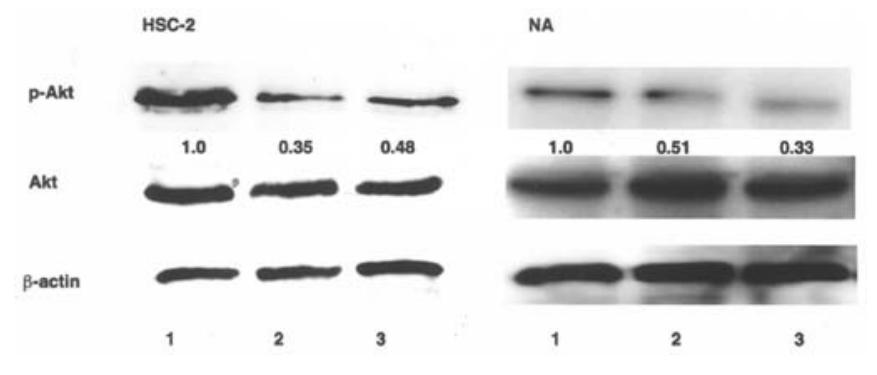

Figure 1. Effect of PI 3-K inhibitors on Akt phosphorylation in HSC-2 and NA cells. HSC-2 (left panel) and NA (right panel) cells were incubated with wortmannin $(500 \mathrm{nM})$ or LY294002 $(30 \mu \mathrm{M})$ for $1 \mathrm{~h}$, then harvested and Akt expression determined using Western blot analysis. All experiments were performed four times independently. Lane 1, untreated; lane 2, wortmannin; lane 3, LY294002. The relative abundances of Akt and p-Akt in untreated and treated cells were normalized to that of $\beta$-actin. Untreated controls were set as 1.0 .

Detection of TRAIL-mediated apoptosis. Annexin V-FITC binding was used as a sensitive method for measuring apoptosis and was performed as described previously, with some modifications $(28,29)$. OSCC cells $\left(1 \times 10^{7}\right.$ cells $\left./ \mathrm{ml}\right)$ were preincubated with or without PI 3-K inhibitor for $2 \mathrm{~h}$. Treated OSCC cells $\left(1 \times 10^{6}\right.$ cells $\left./ \mathrm{ml}\right)$ were exposed to TRAIL (200 ng/ $\mathrm{ml}$ ) for $24 \mathrm{~h}$, then harvested and incubated for $15 \mathrm{~min}$ at room temperature in binding buffer (10 mM HEPES, $140 \mathrm{mM} \mathrm{NaCl}$, $2.5 \mathrm{mM} \mathrm{CaCl}_{2}, \mathrm{pH} 7.4$ ) containing a saturating concentration of annexin V-FITC, according to the manufacturer's protocol. After incubation, cells were pelleted and analyzed using a FACScan flow cytometer and CellQuest software (BectonDickinson Co., Mountain View, CA). A subset of TRAILmediated apoptosis experiments were performed in the presence of caspase inhibitors $(20 \mu \mathrm{M})$.

Mitochondrial membrane potential measurement. Mitochondrial membrane potential determination was performed using the MitoLight apoptosis detection kit (Chemicon Inc., Temecula, CA), which contains the lipophilic mitochondrial activity marker MitoLight. In brief, OSCC cells (1x107 cells/ $\mathrm{ml}$ ) were preincubated with or without PI 3-K inhibitor for $2 \mathrm{~h}$. Treated cells $\left(1 \times 10^{6}\right.$ cells $\left./ \mathrm{ml}\right)$ were then exposed to TRAIL $(200 \mathrm{ng} / \mathrm{ml})$, for $12 \mathrm{~h}$ and harvested. Cells were incubated in MitoLight solution for $20 \mathrm{~min}$, then pelleted and analyzed using a FACScan flow cytometer and CellQuest software (Becton-Dickinson Co.).

Flow cytometric analysis of TRAIL receptor expression. Cell surface expression of TRAIL receptor was determined using indirect immunofluorescence analysis. OSCC cells $\left(1 \times 10^{7}\right.$ cells $\left./ \mathrm{ml}\right)$ were incubated with wortmannin $(500 \mathrm{nM})$ or LY294002 (30 $\mu \mathrm{M})$ for $6 \mathrm{~h}$, after which these cells were treated with a saturating concentration of anti-DR4 or antiDR5 mAb for $40 \mathrm{~min}$. After washing twice with PBS, cells were incubated for $30 \mathrm{~min}$ at $4^{\circ} \mathrm{C}$ with anti-mouse IgG-FITCconjugated secondary $\mathrm{Ab}$ dissolved in PBS containing $0.1 \%$ BSA and $0.1 \%$ sodium azide. Cells were washed again with PBS and fixed with $1 \%$ paraformaldehyde in PBS. Simultaneous negative control staining was performed without primary Ab. Stained cells were analyzed using a FACScan flow cytometer with CellQuest software (Becton-Dickinson Co.). 
(A) HSC-2
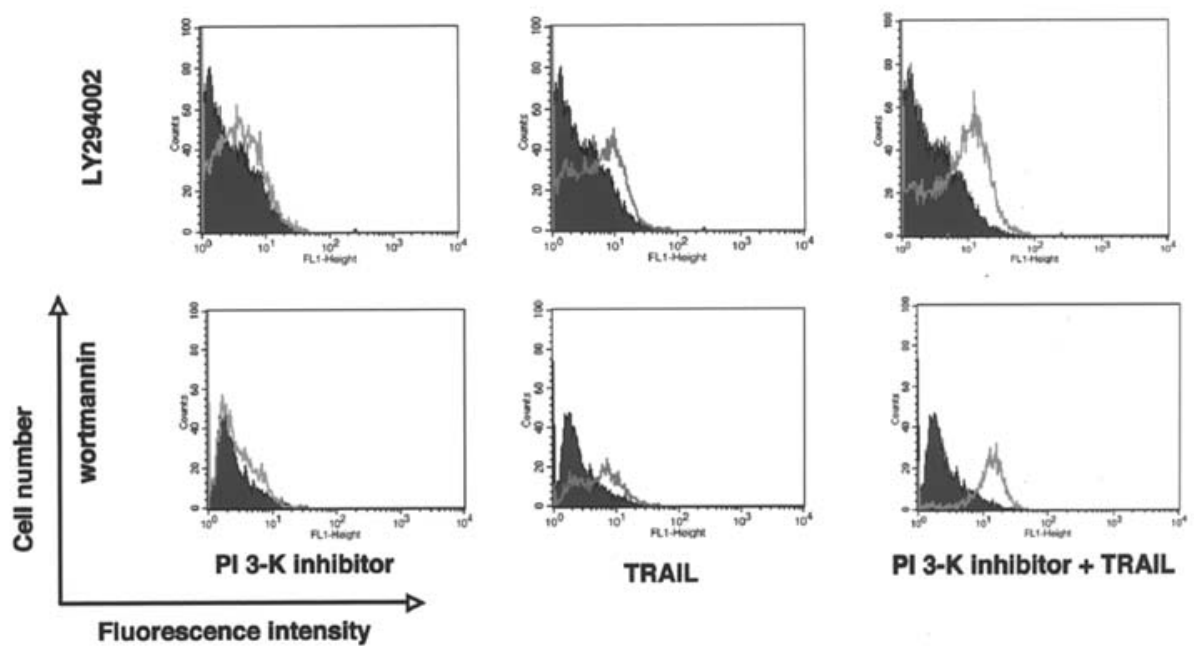

PI 3-K inhlbitor + TRAIL

(B) NA
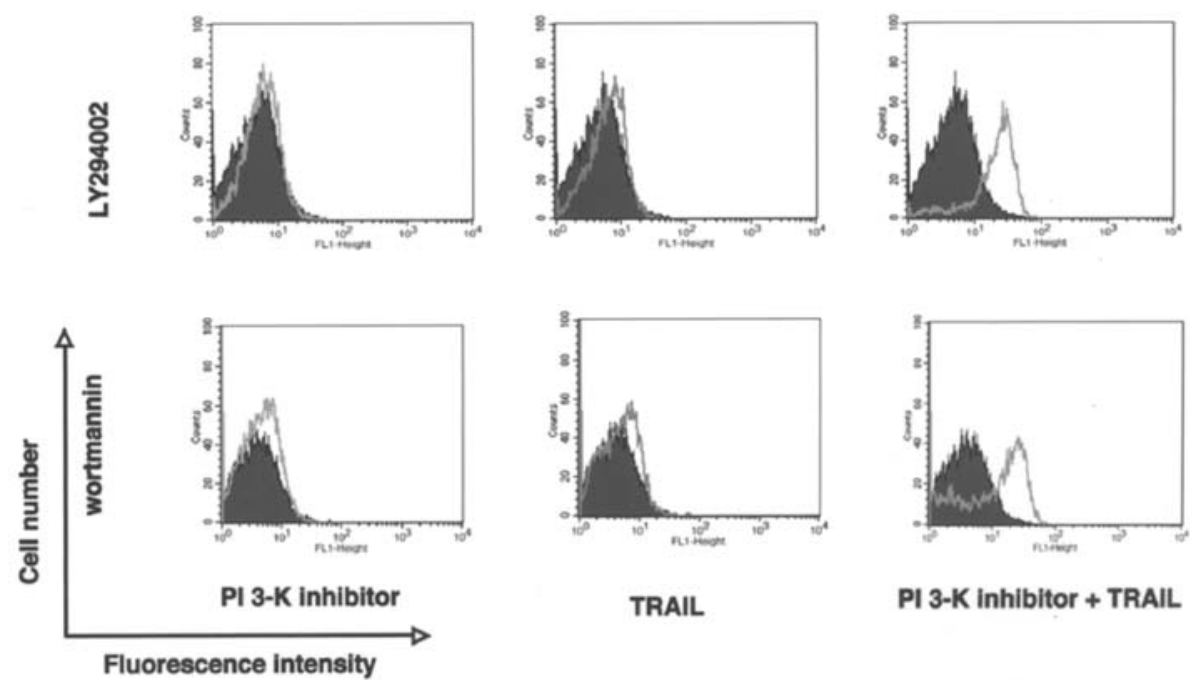

TRAIL

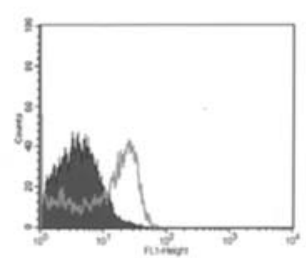

PI 3-K Inhibitor + TRAIL

(C)

HSC-2
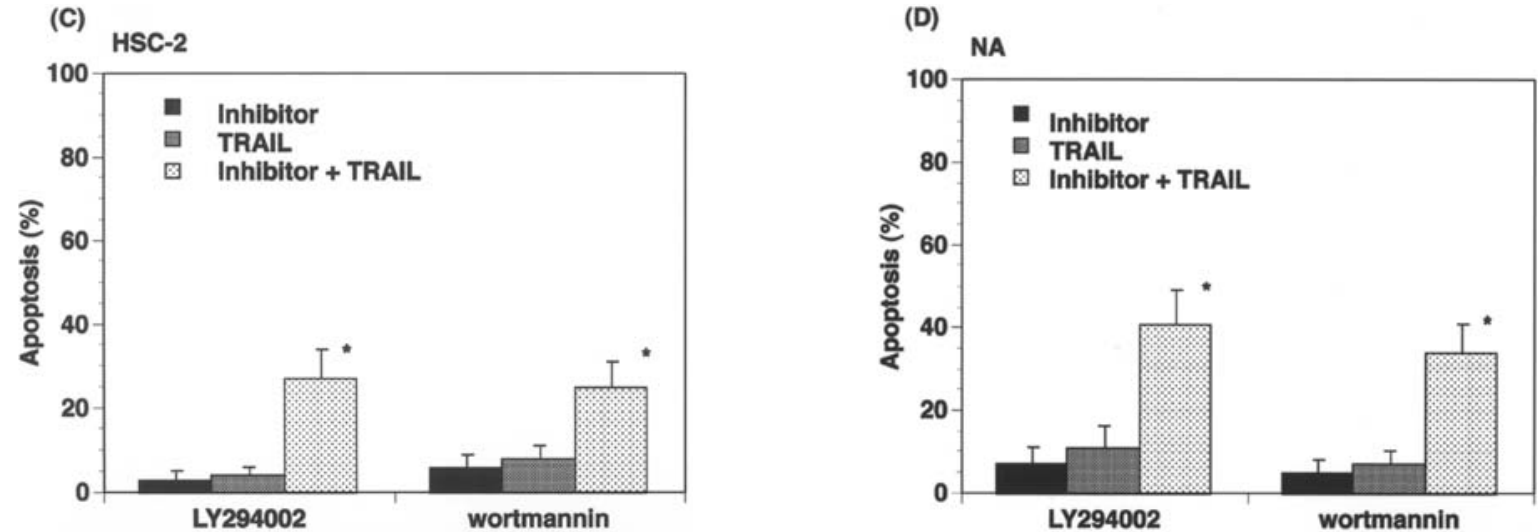

Figure 2. TRAIL-mediated apoptosis in HSC-2 and NA cells treated with PI 3-K inhibitors. Representative histograms of HSC-2 (A) or NA (B) cells treated with $500 \mathrm{nM}$ wortmannin (lower panels, left and right) or $30 \mu \mathrm{M} \mathrm{LY} 294002$ (upper panels, left and right), then $200 \mathrm{ng} / \mathrm{ml}$ recombinant TRAIL (both panels, center and right). Dark and bright lines indicate untreated controls and treated experimental cells, respectively. Percentage of TRAIL-mediated apoptosis in treated HSC-2 (C) or NA (D) cells. Results represent the means \pm SD of four independent experiments. "Statistically significant differences ( $p<0.05)$ between untreated and PI 3-K inhibitor- or TRAIL-treated cells.

Western blot analysis. Western blot analysis was used to detect expression of Akt, p-Akt, c-FLIP, Bax, Bak, Bcl-2, Bcl-xL, cIAP-1, cIAP-2 and XIAP. OSCC cells ( $1 \times 10^{7}$ cells $\left./ \mathrm{ml}\right)$ were incubated with wortmannin $(500 \mathrm{nM})$ or LY294002 $(30 \mu \mathrm{M})$ for $1 \mathrm{~h}$ for detection of Akt and p-Akt, and for $6 \mathrm{~h}$ for detection of c-FLIP, Bax, Bak, Bcl-2, Bcl-xL, cIAP-1, cIAP-2 and XIAP. In the caspase- 8 experiments, PI 3-Ktreated cells were exposed to TRAIL (200 $\mathrm{ng} / \mathrm{ml})$ for $8 \mathrm{~h}$ and then harvested. After treatment, cells $\left(1 \times 10^{7}\right.$ cells $\left./ \mathrm{ml}\right)$ were sedimented and disrupted in lysis buffer containing $50 \mathrm{mM}$ 


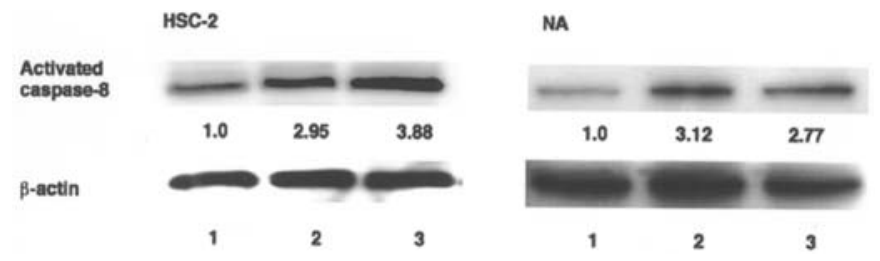

Figure 3. TRAIL-mediated caspase- 8 activation in HSC-2 and NA cells treated with PI 3-K inhibitors. HSC-2 (left panel) and NA (right panel) were treated with or without wortmannin $(500 \mathrm{nM})$ or LY294002 $(30 \mu \mathrm{M})$ for $2 \mathrm{~h}$, then harvested and incubated with recombinant TRAIL $(200 \mathrm{ng} / \mathrm{ml})$ for $8 \mathrm{~h}$. Caspase- 8 activation was determined using Western blot analysis. All experiments were performed four times independently. Lane 1, untreated; lane 2, wortmannin; lane 3, LY294002. The relative abundance of activated caspase- 8 in untreated and treated cells was normalized to that of B-actin. Untreated controls were set as 1.0 .

Tris- $\mathrm{HCl}$ (pH 7.4), $300 \mathrm{mM} \mathrm{NaCl}, 5$ mM EDTA, $0.5 \%$ Triton $\mathrm{X}-100$, with $100 \mathrm{mM}$ sodium o-vanadate and complete mini protease inhibitors (Roche Diagnostics, Mannheim, Germany). Lysates were clarified by centrifugation (15 min, 14,000 x g at $4^{\circ} \mathrm{C}$ ) and protein concentrations measured using the Bradford assay. Proteins $(20 \mu \mathrm{g})$ were separated using SDS-PAGE, then transferred to Hybond PVDF membranes (Amersham Biosciences Corp., Piscataway, NJ). Membranes were blocked for $90 \mathrm{~min}$ in 5\% skim milk blocking buffer at room temperature, then hybridized to a primary $\mathrm{Ab}$ (anti-Akt, -phosphoAkt, -c-FLIP, -Bax, -Bak, -Bcl-2, -Bcl-xL, -cIAP-1, -cIAp-2, -XIAP, -caspase-8), followed by an HRP-conjugated secondary $\mathrm{Ab}$. Protein bands were visualized using the ECL plus Western blot detection system (Amersham Biosciences). B-actin was used as a positive control. Immunoreactive bands were analyzed using a FluoroImager 595 and ImageQuant software (Amersham Biosciences). Background hybridization levels were subtracted from each sample and protein abundances were normalized to that of $B$-actin for each sample. We normalized the results of the experimental proteins to those of the control.

Statistical analysis. The values are presented as the means \pm SD. Data were analyzed using a one-way repeated measure ANOVA. $p<0.05$ was considered to be statistically significant.

\section{Results}

Effect of PI 3-K inhibitors on Akt phosphorylation in OSCC cells. To confirm that the PI 3-K inhibitors wortmannin and LY294002 reduce activation of Akt in HSC-2 and NA cells, we examined Akt phosphorylation. It is likely that Akt is constitutively activated in OSCC cells, as untreated cells exhibited Akt phosphorylation (Fig. 1). Treatment with both PI 3-K inhibitors (500 nM wortmannin and $30 \mu \mathrm{M}$ LY294002) effected down-regulation of Akt phosphorylation (Fig. 1), suggesting that PI 3-K inhibitors can modulate cell survival pathways in OSCC cells.

Effects of PI 3-K inhibitors on TRAIL-mediated apoptosis. We examined the annexin V binding of HSC-2 and NA cells treated with PI 3-K inhibitors, in order to determine whether or not they exhibited altered susceptibility to TRAIL-mediated apoptosis. Untreated HSC-2 and NA cells were relatively resistant to TRAIL-mediated apoptosis, whereas apoptosis levels were significantly higher in PI 3-K inhibitor-treated cells (Fig. 2). Spontaneous apoptosis did not appear to be elevated by either of the PI 3-K inhibitor treatments (Fig. 2). As trimerization of TRAIL receptors by a TRAIL trimer leads to recruitment of an adaptor Fas-associated death domain protein, which in turn recruits and activates caspase-8 $(4,13)$, We investigated the abundance of activated caspase- 8 in PI 3-K inhibitor-treated cells following incubation with TRAIL. In the presence of TRAIL, PI 3-K inhibitor-treated cells exhibited a marked increase in abundance of activated caspase- 8 relative to untreated cells (Fig. 3), suggesting that the pro-apoptotic activities of these inhibitors are involved in the caspase- 8 and -3 pathways of the caspase cascade. In addition, these results suggest that the pro-apoptotic effect of PI 3-K inhibitors may act upstream of caspase- 8 activation in TRAIL-mediated apoptosis. Caspase-3-mediated cellular apoptosis requires amplification through the mitochondrial pathway, initiated by caspase- 8 cleavage of Bid and translocation of the truncated Bid fragment into mitochondria, leading to a Bax/Bak-mediated release of cytochrome $\mathrm{c}$ and caspase- 9 activation by Apaf-1 $(4,13)$. Thus, we examined whether or not there is an alteration of mitochondrial membrane potential in OSCC cells treated with PI 3-K inhibitors during TRAIL-mediated apoptosis, and observed a marked loss in comparison to untreated cells (Fig. 4). These results suggest that the pro-apoptotic effect of PI 3-K inhibitors on TRAILmediated apoptosis may contribute to the intrinsic pathway. Next, we examined whether or not caspase inhibitors affect the pro-apoptotic activities of PI 3-K inhibitors. We observed that inhibitors of caspase- $3,-8$ and -9 reduce the accelerative
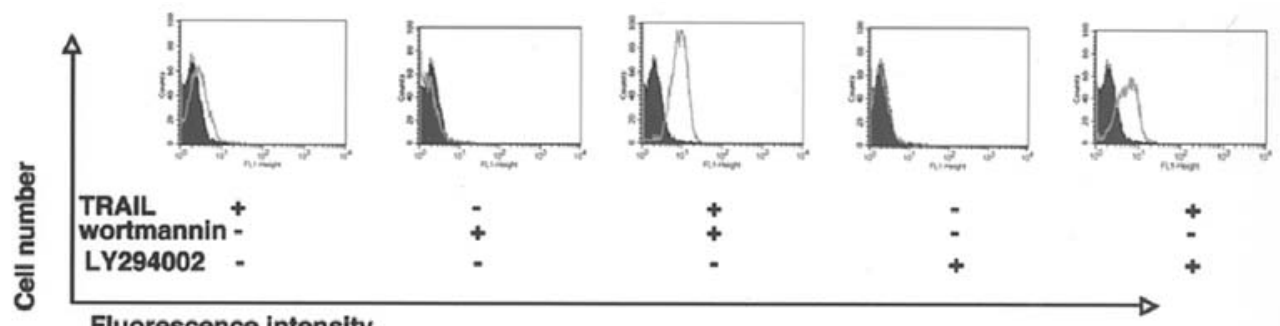

Figure 4. TRAIL-mediated mitochondrial membrane potential of HSC-2 cells treated with PI 3-K inhibitors. HSC-2 cells were treated with or without wortmannin $(500 \mathrm{nM})$ or LY294002 $(30 \mu \mathrm{M})$ for $2 \mathrm{~h}$, then harvested and incubated with recombinant TRAIL (200 ng/ml) for $12 \mathrm{~h}$. Mitochondrial membrane potential was determined using flow cytometry and the histograms represent typical results. All experiments were performed four times independently. Dark and light lines indicate untreated controls and treated experimental cells, respectively. 
(A)

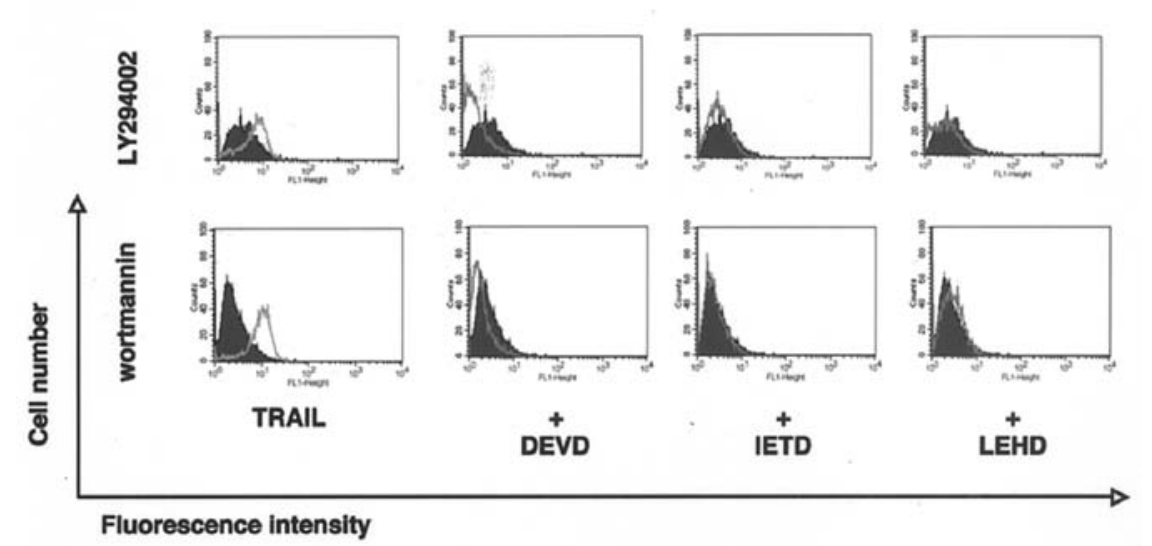

(B)

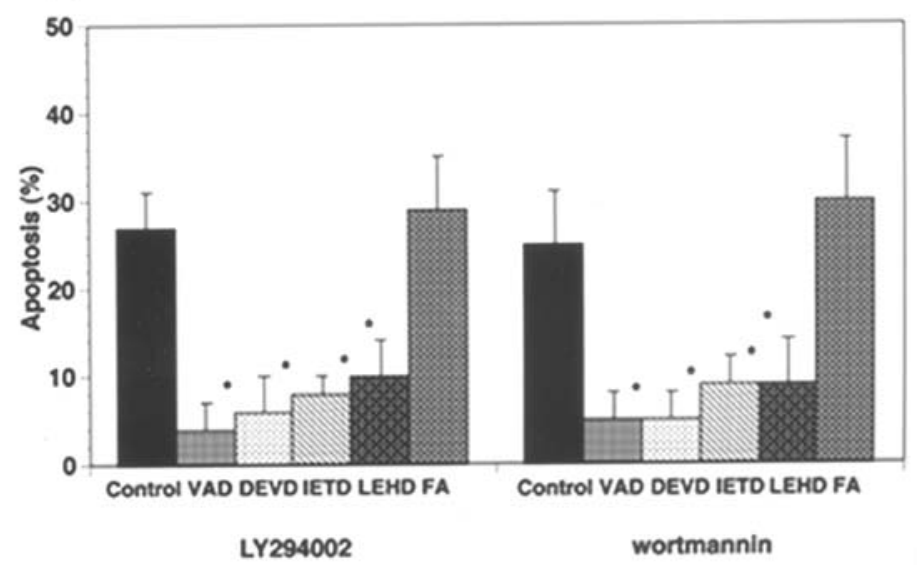

Figure 5. Effect of caspase inhibitors on TRAIL-mediated apoptosis in HSC-2 cells treated with PI 3-K inhibitors. HSC-2 cells were treated with or without wortmannin $(500 \mathrm{nM})$ or LY294002 $(30 \mu \mathrm{M})$ for $2 \mathrm{~h}$, then harvested and incubated for $24 \mathrm{~h}$ with recombinant TRAIL ( $200 \mathrm{ng} / \mathrm{ml})$ and the caspase inhibitors indicated $(20 \mu \mathrm{M})$. (A) Representative histograms of TRAIL-mediated apoptosis in HSC-2 cells treated with wortmannin (left) or LY294002 (right) and caspase inhibitors. Dark and light lines indicate untreated controls and treated experimental cells, respectively. (B) Percentage of TRAIL-mediated apoptosis in HSC-2 cells treated with wortmannin (left) or LY294002 (right) and caspase inhibitors. Results represent the mean \pm SD of four independent experiments. *Statistically significant differences $(\mathrm{p}<0.05)$ between the presence and absence of caspase inhibitors in TRAIL-treated cells.

effect of PI 3-K inhibitors on TRAIL-induced apoptosis of OSCC cells (Fig. 5). Thus, the pro-apoptotic activity of PI 3-K inhibitors is related to both the extrinsic and intrinsic pathways within the caspase cascade.

Effect of PI 3-K inhibitors on TRAIL receptor expression. To investigate whether or not the expression of TRAIL receptors was altered by treatment with PI 3-K inhibitors, we examined expression of DR4 and DR5 using a FACScan flow cytometer. TRAIL induces apoptosis by binding either the DR4 or DR5 receptor, resulting in activation of the extrinsic pathway $(4,13)$. Both DR4 and DR5 were expressed constitutively and we observed no significant difference following addition of either wortmannin or LY294002 (Fig. 6). Therefore, these data indicate that the acceleration of TRAIL-mediated apoptosis observed with PI 3-K inhibitor treatment was not a consequence of increased TRAIL receptor expression.

Effect of PI 3-K inhibitors on c-FLIP expression. Overexpression of c-FLIP is an established mechanism for resistance to TRAIL-mediated apoptosis $(4,13)$. Following treatment with PI 3-K inhibitors, we examined the level of c-FLIP expression using Western blot analysis. c-FLIP was expressed constitutively in both HSC-2 and NA cells, whereas following treatment with PI 3-K inhibitors there was a marked decrease in its expression (Fig. 7). These results suggest that in OSCC cells, the PI 3-K/Akt signaling pathway can modulate TRAILmediated apoptosis via expression of c-FLIP.

Effect of PI 3-K inhibitors on expression of Bcl-2 family proteins. Members of the Bcl-2 family are important factors in the modulation of TRAIL-mediated apoptosis $(4,13)$. Therefore, we examined the effect of PI 3-K inhibitors on expression of Bak, Bax, Bcl-2 and Bcl-xL in HSC-2 cells. Treatment with both wortmannin and LY294002 increased expression levels of the pro-apoptotic protein Bax and downregulated the anti-apoptotic protein Bcl-2 (Fig. 8). In contrast, expression of the anti-apoptotic protein $\mathrm{Bcl}-\mathrm{xL}$ and the proapoptotic protein Bak were unaffected by this treatment (Fig. 8). These results suggest that in OSCC cells, the PI 3-K/ Akt signaling pathway may modulate TRAIL-mediated apoptosis via regulation of Bcl-2 family proteins such as Bax and Bcl-2.

Effect of PI 3-K inhibitors on expression of IAP family proteins. Members of the IAP family also contribute to 
(A)

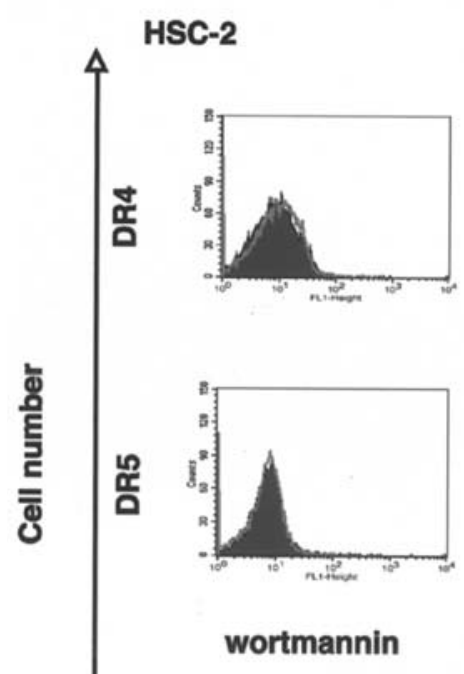

Bcl-2
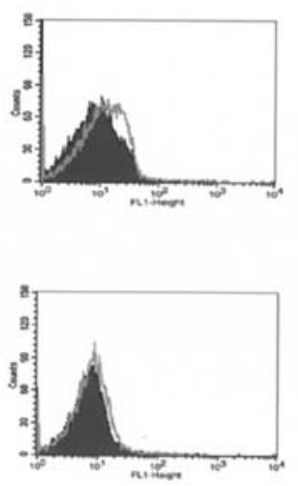

LY294002

Fluorescence intensity

(B)

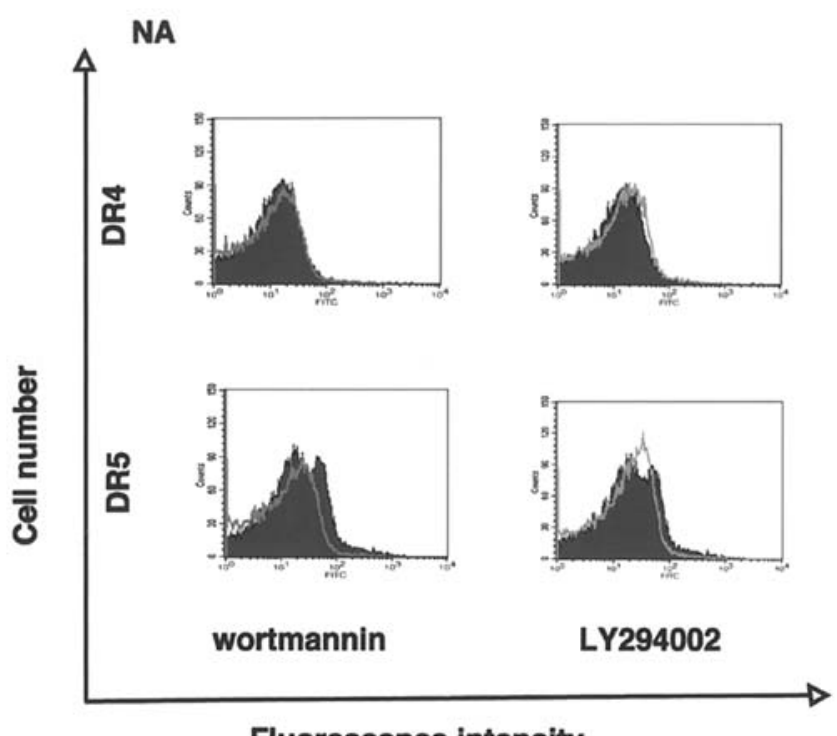

Fluorescence intensity

Figure 6. Expression of the TRAIL receptors DR4 and DR5 on HSC-2 and NA cells treated with PI 3-K inhibitors. Representative histograms of (A) HSC-2 and (B) NA cells treated with wortmannin (500 nM, left) or LY294002 (30 $\mu \mathrm{M}$, right) for $12 \mathrm{~h}$, then harvested and assayed for expression of DR4 (top panels) and DR5 (lower panels) on the cell membrane. Experiments were performed four times independently. Dark and light lines indicate untreated controls and treated experimental cells, respectively.
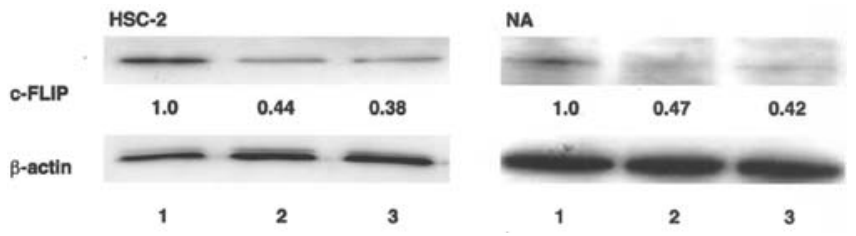

Figure 7. Effects of PI 3-K inhibitors on c-FLIP expression in HSC-2 and NA cells. HSC-2 (left) and NA (right) cells were treated with wortmannin $(500 \mathrm{nM})$ or LY294002 $(30 \mu \mathrm{M})$ for $6 \mathrm{~h}$, then harvested and c-FLIP expression was determined using Western blot analysis. All experiments were performed four times independently. Lane 1, untreated; lane 2, wortmannin; lane 3, LY294002. The relative abundance of c-FLIP in untreated and treated cells was normalized to that of $\beta$-actin. Untreated controls were set as 1.0.

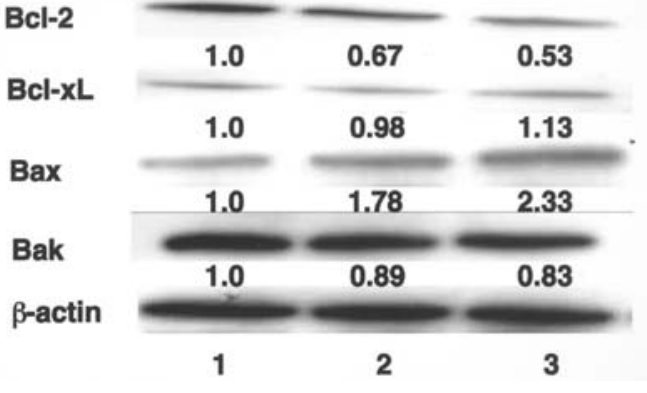

Figure 8. Effects of PI 3-K inhibitors on expression of Bcl-2 family proteins in HSC-2 cells. HSC-2 cells were treated with wortmannin $(500 \mathrm{nM})$ or LY294002 $(30 \mu \mathrm{M})$ for $6 \mathrm{~h}$, then harvested and Bcl-2 family protein expression was determined using Western blot analysis. All experiments were performed four times independently. Lane 1, untreated; lane 2, wortmannin; lane 3, LY294002. The relative abundances of Bcl-2 family proteins in untreated and treated cells were normalized to that of $B$-actin. Untreated controls were set as 1.0.

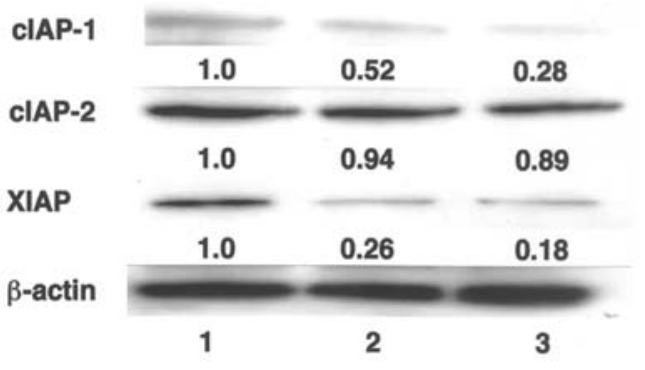

Figure 9. Effects of PI 3-K inhibitors on expression of IAP family proteins in HSC-2 cells. HSC-2 cells were treated with wortmannin $(500 \mathrm{nM})$ or LY294002 $(30 \mu \mathrm{M})$ for $6 \mathrm{~h}$, then harvested and IAP family protein expression was determined using Western blot analysis. All experiments were performed four times independently. Lane 1, untreated; lane 2, wortmannin; lane 3, LY294002. The relative abundances of IAP family proteins in untreated and treated cells were normalized to that of $\beta$-actin. Untreated controls were set as 1.0.

susceptibility to TRAIL-mediated apoptosis $(4,13)$ and we examined the effect of PI $3-\mathrm{K}$ inhibitors on expression of cIAP-1, cIAP-2 and XIAP in HSC-2 cells. Treatment with both wortmannin and LY294002 down-regulated expression of cIAP-1 and XIAP, but did not alter expression of cIAP-2 (Fig. 9). These results suggest that in OSCC cells, the PI 3-K/ Akt signaling pathway may also modulate TRAIL-mediated apoptosis via regulation of IAP family proteins such as cIAP-1 and XIAP.

\section{Discussion}

PI 3-K/Akt suppresses apoptosis mediated by both ligation of death receptors and the mitochondrial pathway $(18,22-24)$. Treatment with PI 3-K inhibitors (wortmannin and LY294002) caused marked suppression of Akt phosphorylation in the OSCC cell lines HSC-2 and NA (Fig. 1). These results suggest that the PI 3-K/Akt pathway plays a role in OSCC cell survival and that PI 3-K inhibitors can induce apoptosis in these cells.

PI 3-K inhibitors such as wortmannin and LY294002 are known to possess anti-tumor activities $(30,31)$ and previous studies have indicated that the PI 3-K/Akt signaling pathway 
can modulate TRAIL-mediated apoptosis in cancer cells (22-24,32,33). Therefore, we used HSC-2 and NA cell lines, which are resistant to TRAIL-induced apoptosis, to examine the effect of treatment with PI 3-K inhibitors on susceptibility to apoptosis via this process. We demonstrated that in OSCC cells, TRAIL-mediated apoptosis is significantly enhanced by treatment with PI 3-K inhibitors (Fig. 2) and that this treatment results in activation of caspase-8 (Fig. 3) and loss of mitochondrial membrane potential (Fig. 4).

Next, we investigated the effect of various caspase inhibitors on the enhancement of TRAIL-induced apoptosis by PI 3-K inhibitors and observed that inhibitors of caspase- $3,-8$ or -9 reduced the effect of PI 3-K inhibitors (Fig. 5). These results suggest that in PI 3-K inhibitor-treated OSCC cells, TRAILinduced apoptosis is related to both the extrinsic and intrinsic pathways.

Up-regulation of TRAIL receptor expression may provide an explanation for the amplification of TRAIL-induced apoptosis effected by PI 3-K inhibitors. Previous studies have shown that in cancer cells, expression of TRAIL receptors is modulated by extracellular stimuli such as anti-cancer drugs, radiation and cytokines, all of which amplify cellular susceptibility to TRAIL-mediated apoptosis (6,34-36). In contrast, other studies have shown that TRAIL receptor expression is not altered by pro- or anti-apoptotic stimuli $(27,33,37)$. Thus, we examined whether or not DR4 or DR5 expression was altered by treatment with PI 3-K inhibitors and observed no significant change (Fig. 6), confirming the results of earlier studies (22-24). Interestingly, other studies have also demonstrated that DR4 and DR5 expression levels do not correlate with susceptibility to TRAIL-induced apoptosis $(37,38)$. These results also suggest that the pro-apoptotic activity of PI 3-K inhibitors dose not contribute to expression of DR4 or DR5.

c-FLIP is a proximal regulator during TRAIL-mediated apoptosis $(4,10,13)$ and high levels of this protein have been related to resistance to TRAIL-mediated apoptosis $(4,10,13,39)$. c-FLIP is a competitive inhibitor of caspase- 8 for binding to the TRAIL receptor complex and thus, its activity downregulates the downstream TRAIL signaling pathway $(4,13,39)$. In cancer cells, c-FLIP expression levels are higher than in normal tissue and these elevated levels allow the cells to overcome TRAIL-mediated apoptosis $(40,41)$. Furthermore, recent studies, including our previous investigations, have indicated that transfection of small interfering RNA or antisense oligonucleotides against c-FLIP enhanced death receptor-induced apoptosis in various cancer cells $(28,42,43)$. As caspase- 8 inhibitors suppressed increased TRAIL-mediated apoptosis caused by PI 3-K inhibitors, the pro-apoptotic effect of the latter group may act upstream of caspase-8 activation.

Elevated Akt activity up-regulates c-FLIP and inhibits TRAIL-mediated apoptosis in various cancer cells $(22,23,42,44)$ and PI $3-K$ inhibitors down-regulate the expression of c-FLIP in cancer cells $(27,29)$. Thus, we investigated c-FLIP expression in PI 3-K inhibitor-treated OSCC cells and observed that c-FLIP was strongly downregulated by both wortmannin and LY294002 (Fig. 7). Therefore, down-regulation of c-FLIP expression represents a pro-apoptotic factor in the effects of PI $3-\mathrm{K}$ inhibitor on TRAIL-mediated apoptosis.
In this study, mitochondrial membrane potential was lost following addition of TRAIL to PI 3-K inhibitor-treated OSCC cells and the caspase-9 inhibitor suppressed this process. These results indicate that the pro-apoptotic activity of PI 3-K inhibitors is related to the intrinsic pathway. Previously, we have shown that wortmannin and LY294002 also inhibited Bad phosphorylation in OSCC cells (29); phosphorylated $\mathrm{Bad}$ is known to bind mitochondrial Bcl-2 or Bcl-xL, preventing cytochrome c release and caspase- 9 activation (45). Previous reports have also suggested that Akt-related TRAIL resistance is mediated via inhibition of Bid cleavage and that the pro-apoptotic activity of PI 3-K inhibitors is linked to the intrinsic pathway $(22,32)$. The intrinsic pathway is regulated by pro- and anti-apoptotic proteins which include members of the Bcl-2 and IAP families and TRAIL resistance can be mediated at the mitochondrial level by Bcl-2 and Bcl-xL $(4,13,46)$. The IAP family of caspase inhibitors act predominantly as downstream inhibitors of TRAIL pathways; they are expressed at high levels in various cancer cells, suggesting that they play a key role in preventing apoptosis $(4,13,47)$. Here we have shown that in OSCC cells, PI 3-K inhibitors down-regulate the anti-apoptotic proteins Bcl-2, cIAP-1 and XIAP, and up-regulate the pro-apoptotic protein Bax. Thus, the PI 3-K inhibitors may enhance TRAIL-mediated apoptosis in OSCC cells by modulation of apoptosis-regulated protein levels. Although previous studies have shown that PI 3-K inhibitors regulate expression of various members of the $\mathrm{Bcl}-2$ and IAP families, these results do not necessary hold across different cancer cell types $(22,23,32)$. In order to elucidate fully the role played by these families in TRAIL-mediated apoptosis of different cancer cell types, it will be necessary to perform knockdown and overexpression analyses. In cancer cells, Akt is activated constitutively, promoting cellular survival and resistance to chemotherapy, ionizing radiation, Fas and TRAIL $(23,48)$. However, anti-cancer drugs and radiation suppress PI 3-K/ Akt activation, inducing cell death $(49,50)$. Recent reports have demonstrated that anti-cancer drugs and PI 3-K inhibitors can act synergistically in malignant tumors $(51,52)$. This suggests that a combined approach may be effective for activating death receptors and TRAIL-dependent apoptosis in OSCC cells.

In conclusion, we found that PI 3-K/Akt inactivation induced TRAIL-mediated apoptosis in OSCC cells via downregulation of c-FLIP, Bcl-2, cIAP-1 and XIAP, and upregulation of Bax. Our results therefore, support the hypothesis that targeting of the PI 3-K/Akt signaling pathway is a powerful strategy for overcoming OSCC cell resistance to conventional therapeutic treatments. As such, pharmacological inhibitors of the PI 3-K/Akt signaling pathway might achieve this aim: recent studies have demonstrated that agonistic mAbs against DR4 and DR5 can induce apoptosis in a variety of cultured and primary cancer cells (53). Other studies have shown that the combination of anti-human DR4 and DR5 mAbs with chemotherapeutic drugs or radiotherapy synergistically enhanced anti-tumor effects $(54,55)$. Given the inherent difficulties of using wortmannin and LY294002 (stability, solubility and toxicity), efforts are underway to develop new PI 3-K pathway inhibitors; recently, a novel candidate has been reported that exhibits strong anti-tumor activity against human cancers without concomitant toxic effects on organs (56). 


\section{References}

1. Wiley SR, Schooley K, Smolak PJ, et al: Identification and characterization of a new member of the TNF family that induces apoptosis. Immunity 3: 1995: 673-682, 1995.

2. Pitti RM, Marsters SA, Ruppert S, Donahue CJ, Moore A and Ashkenazi A: Induction of apoptosis by Apo-2 ligand, a new member of the tumor necrosis factor cytokine family. J Biol Chem 271: 12687-12690, 1996.

3. Green DR: Apoptotic pathways: paper wraps stone blunts scissors. Cell 102: 1-4, 2000.

4. Ashkenazi A: Targeting death and decoy receptors of the tumornecrosis factor superfamily. Nat Rev Cancer 2: 420-430, 2002.

5. Younes A and Kadin ME: Emerging applications of the tumor necrosis factor family of ligands and receptors in cancer therapy. J Clin Oncol 21: 3526-3534, 2003.

6. Kondo K, Yamasaki S, Sugie T, et al: Cisplatin-dependent upregulation of death receptor 4 and 5 augments induction of apoptosis by TNF-related apoptosis-inducing ligand against esophageal squamous cell carcinoma. Int J Cancer 118: 230-242, 2006.

7. Lawrence D, Shahrokh Z, Marsters S, et al: Differential hepatocyte toxicity of recombinant Apo2L/TRAIL versions. Nat Med 7: 383-385, 2001

8. Ehrhardt H, Fulda S, Schmid I, Hiscott J, Debatin KM and Jeremias I: TRAIL induced survival and proliferation in cancer cells resistant towards TRAIL-induced apoptosis mediated by NFKB. Oncogene 22: 3842-3852, 2003.

9. Jarpe MB, Widmann C, Knall C, et al: Anti-apoptotic versus pro-apoptotic signal transduction: checkpoints and stop signs along the road to death. Oncogene 17: 1475-1482, 1998.

10. Irmler M, Thome M, Hahne M, et al: Inhibition of death receptor signals by cellular FLIP. Nature 388: 190-195, 1997.

11. Chao DT and Korsmeyer SJ: BCL-2 family: regulators of cell death. Annu Rev Immunol 16: 395-419, 1998.

12. Wang CY, Mayo MW, Korneluk RG, Goeddel DV and Baldwin AS: NF- $\mathrm{KB}$ antiapoptosis: induction of TRAF1 and TRAF2 and c-IAP1 and c-IAP2 to suppress caspase-8 activation. Science 281: 1680-1683, 1998.

13. Yagita H, Takeda K, Hayakawa Y, Smyth MJ and Okumura K: TRAIL and its receptors as targets for cancer therapy. Cancer Sci 95: 777-783, 2004.

14. Sheridan JP, Marsters SA, Pitti RM, et al: Control of TRAILinduced apoptosis by a family of signaling and decoy receptors. Science 277: 818-821, 1997.

15. Lee SH, Shin MS, Kim HS, et al: Somatic mutations of TRAILreceptor 1 and TRAIL-receptor 2 genes in non-Hodgkin's lymphoma. Oncogene 20: 399-403, 2001.

16. Deng Y, Lin Y and Wu X: TRAIL-induced apoptosis requires Bax-dependent mitochondrial release of Smac/DIABLO. Genes Dev 16: 33-45, 2002

17. Leverkus M, Sprick MR, Wachter T, et al: Proteasome inhibition results in TRAIL sensitization of primary keratinocytes by removing the resistance-mediating block of effector caspase maturation. Mol Cell Biol 23: 777-790, 2003.

18. Datta SR, Brunet A and Greenberg M: Cellular survival: a play in three Akts. Genes Dev 13: 2905-2927, 1999.

19. Vivanco I and Sawyers CL: The phosphatidylinositol 3-kinase AKT pathway in human cancer. Nat Rev Cancer 2: 489-501, 2002.

20. Luo J, Manning BD and Cantley LC: Targeting the PI3K-Akt pathway in human cancer: rationale and promise. Cancer Cell 4: 257-262, 2003.

21. Dudek H, Datta SR, Franke TF, et al: Regulation of neuronal survival by the serine-threonine protein kinase Akt. Science 275: 661-665, 1997.

22. Nesterov A, Lu X, Johnson M, Miller GJ, Ivashchenko Y and Kraft AS: Elevated AKT activity protects the prostate cancer cell line LNCaP from TRAIL-induced apoptosis. J Biol Chem 276: 10767-10774, 2001

23. Chen X, Thakkar H, Tyan F, et al: Constitutively active Akt is an important regulator of TRAIL sensitivity in prostate cancer. Oncogene 20: 6073-6083, 2001.

24. Kandasamy K and Srivastava RK: Role of the phosphatidylinositol 3'-kinase/PTEN/Akt kinase pathway in tumor necrosis factor-related apoptosis-inducing ligand-induced apoptosis in nonsmall cell lung cancer cells. Cancer Res 62: 4929-4937, 2002.

25. Panka DJ, Mano T, Suhara T, Walsh K and Mier JW: Phosphatidylinositol 3-kinase/Akt activity regulates c-FLIP expression in tumor cells. J Biol Chem 276: 6893-6896, 2001.
26. Hersey P and Zhang XD: Overcoming resistance of cancer cells to apoptosis. J Cell Physiol 196: 9-18, 2003.

27. Nam SY, Jung GA, Hur GC, et al: Upregulation of FLIP(S) by Akt, a possible inhibition mechanism of TRAIL-induced apoptosis in human gastric cancers. Cancer Sci 94: 1066-1073, 2003.

28. Iwase M, Watanabe H, Kondo G, Ohashi M and Nagumo M: Enhanced susceptibility of oral squamous cell carcinoma cell lines to Fas-mediated apoptosis by cisplatin and 5-fluorouracil. Int J Cancer 106: 619-625, 2003.

29. Kondo G, Iwase M, Watanabe H, et al: Enhancement of susceptibility to Fas-mediated apoptosis in oral squamous cell carcinoma cells by phosphatidylinositol 3-kinase inhibitor. Oral Oncol 42: 745-752, 2006.

30. Lemke LE, Paine-Murrieta GD, Taylor CW and Powis G: Wortmannin inhibits the growth of mammary tumors despite the existence of a novel wortmannin-insensitive phosphatidylinositol-3-kinase. Cancer Chemother Pharmacol 44: 491-497, 1999.

31. Semba S, Itoh $N$, Ito $M$, Harada $M$ and Yamakawa $M$ : The in vitro and in vivo effects of 2-(4-morpholinyl)-8-phenylchromone (LY294002), a specific inhibitor of phosphatidylinositol 3'-kinase, in human colon cancer cells. Clin Cancer Res 8: 1957-1963, 2002

32. Thakkar $\mathrm{H}$, Chen $\mathrm{X}$, Tyan $\mathrm{F}$, et al: Pro-survival function of Akt/protein kinase B in prostate cancer cells. Relationship with TRAIL resistance. J Biol Chem 276: 38361-38369, 2001.

33. Puduvalli VK, Sampath D, Bruner JM, Nangia J, Xu R and Kyritsis AP: TRAIL-induced apoptosis in gliomas is enhanced by Akt-inhibition and is independent of JNK activation. Apoptosis 10: 233-243, 2005.

34. Chinnaiyan AM, Prasad U, Shankar S, et al: Combined effect of tumor necrosis factor-related apoptosis-inducing ligand and ionizing radiation in breast cancer therapy. Proc Natl Acad Sci USA 97: 1754-1759, 2000.

35. Nagane M, Pan G, Weddle JJ, Dixit VM, Cavenee WK and Huang $\mathrm{H}$ : Increased death receptor 5 expression by chemotherapeutic agents in human gliomas causes synergistic cytotoxicity with tumor necrosis factor-related apoptosis-inducing ligand in vitro and in vivo. Cancer Res 60: 847-853, 2000.

36. Singh TR, Shankar S, Chen X, Asim M and Srivastava R: Synergistic interactions of chemotherapeutic drugs and tumor necrosis factor-related apoptosis-inducing ligand/Apo-2 ligand on apoptosis and on regression of breast carcinoma in vivo. Cancer Res 63: 5390-5400, 2003.

37. Kim JH, Ajaz M, Lokshin A and Lee YJ: Role of antiapoptotic proteins in tumor necrosis factor-related apoptosis-inducing ligand and cisplatin-augmented apoptosis. Clin Cancer Res 9: 3134-3141, 2003

38. Keane MM, Ettenberg SA, Nau MM, Russell EK and Lipkowitz S: Chemotherapy augments TRAIL-induced apoptosis in breast cell lines. Cancer Res 59: 734-741, 1999.

39. Krueger A, Baumann S, Krammer PH and Kirchhoff S: FLICEinhibitory proteins: regulators of death receptor-mediated apoptosis. Mol Cell Biol 21: 8247-8254, 2001.

40. Ryu BK, Lee MG, Chi SG, Kim YW and Park JH: Increased expression of cFLIP(L) in colonic adenocarcinoma. J Pathol 194: 15-19, 2001

41. Rippo MR, Moretti S, Vescovi S, et al: FLIP overexpression inhibits death receptor-induced apoptosis in malignant mesothelial cells. Oncogene 24: 7753-7760, 2004.

42. Chawla-Sarkar M, Bae SI, Reu FJ, Jacobs BS, Lindner DJ and Borden EC: Downregulation of Bcl-2, FLIP or IAPs (XIAP and survivin) by siRNAs sensitizes resistant melanoma cells to Apo2L/TRAIL-induced apoptosis. Cell Death Differ 11: 915-923, 2004.

43. Sharp DA, Lawrence DA and Ashkenazi A: Selective knockdown of the long variant of cellular FLICE inhibitory protein augments death receptor-mediated caspase- 8 activation and apoptosis. J Biol Chem 280: 19401-19409, 2005.

43. Kang YC, Kim KM, Lee KS, et al: Serum bioactive lysophospholipids prevent TRAIL-induced apoptosis via PI3K/Aktdependent cFLIP expression and Bad phosphorylation. Cell Death Differ 11: 1287-1298, 2004

45. Kennedy SG, Kandel ES, Cross TK and Hay N: Akt/Protein kinase $B$ inhibits cell death by preventing the release of cytochrome c from mitochondria. Mol Cell Biol 19: 5800-5810, 1999.

46. Ray S, Bucur O and Almasan A: Sensitization of prostate carcinoma cells to Apo2L/TRAIL by a Bcl-2 family protein inhibitor. Apoptosis 10: 1411-1418, 2005. 
47. Salvesen GS and Duckett CS: IAP proteins: blocking the road to death's door. Nat Rev Mol Cell Biol 3: 401-410, 2002.

48. Brognard J, Clark AS, Ni Y and Dennis PA: Akt/protein kinase $\mathrm{B}$ is constitutively active in non-small cell lung cancer cells and promotes cellular survival and resistance to chemotherapy and radiation. Cancer Res 61: 3986-3997, 2001.

49. Nakashio A, Fujita N, Rokudai S, Sato S and Tsuruo T: Prevention of phosphatidylinositol 3'-kinase-Akt survival signaling pathway during topotecan-induced apoptosis. Cancer Res 60: 5303-5309, 2000.

50. Tenzer A, Zingg D, Rocha S, et al: The phosphatidylinositol 3'kinase/Akt survival pathway is a target for the anticancer and radiosensitizing agent $\mathrm{PKC} 412$, an inhibitor of protein kinase $\mathrm{C}$. Cancer Res 61: 8203-8210, 2001.

51. Shingu T, Yamada K, Hara N, et al: Synergistic augmentation of antimicrotubule agent-induced cytotoxicity by phosphainositide 3-kinase inhibitor in human malignant glioma cells. Cancer Res 63: 4044-4047, 2003.

52. Hu L, Hofmann J, Lu Y, Mills GB and Jaffe RB: Inhibition of phosphatidylinositol 3'-kinase increases efficacy of paclitaxel in vitro and in vivo ovarian cancer models. Cancer Res 62: 1087-1092, 2002.
53. Pukac L, Kanakaraj P, Humphreys R, et al: HGS-ETR1, a fully human TRAIL-receptor 1 monoclonal antibody, induces cell death in multiple tumor types in vitro and in vivo. Br J Cancer 92: 1430-1441, 2005.

54. Georgakis GV, Li Y, Humphreys R, et al: Activity of selective fully human agonistic antibodies to the TRAIL death receptors TRAIL-R1 and TRAIL-2 in primary and cultured lymphoma cells: induction of apoptosis and enhancement of doxorubicinand bortezomib-induced cell death. Br J Haematol 130: 501-510, 2005.

55. Marini P, Denzinger S, Schiller D, et al: Combined treatment of colorectal tumors with agonistic TRAIL receptor antibodies HGS-ETR1 and HGS-ETR2 and radiotherapy: enhanced effects in vitro and dose-dependent growth delay in vivo. Oncogene 25: 5145-5154, 2006

56. Yaguchi S, Fukui Y, Koshimizu I, et al: Antitumor activity of ZSTK474, a new phosphatidylinositol 3-kinase inhibitor. J Natl Cancer Inst 98: 545-556, 2006. 